\title{
Diversity Analysis and Hybridity Test of Drought Responsive Wheat Cultivars and their F1's on the Basis of SDS-PAGE Profiles
}

\author{
Usha Pant* and V.K. Khanna \\ Department of Genetics and Plant Breeding, College of Agriculture, G. B. Pant University of \\ Agriculture and Technology, Pantnagar- 263 145, India \\ *Corresponding author
}

A B S T R A C T

\section{Keywords}

Electrophoresis, protein polymorphism, SDS PAGE, Wheat

Article Info

Accepted:

22 May 2018

Available Online:

10 June 2018
The genetic polymorphism revealed by biochemical markers (protein and isozymes) in plant population have been extensively used to, assess the genetic variability, confirm hybridity of $\mathrm{F}_{1} \mathrm{~s}$, assure purity of cultivar and establish relationship between species. Electrophoretic protein analysis holds potential utility in breeding programmes of wheat through helping in the unequivocal characterization of varieties used. Sixteen wheat genotypes along with their $32 \mathrm{~F}_{1}$ 's were characterized by using protein profile polymorphism in seeds through SDS-PAGE. The total number of bands varied from 9-17 with arrange of $3000 \mathrm{kd}$ to $20,100 \mathrm{kd}$. The similarity coefficient ranged from $0.985-0.632$ among parental lines. The dendrogram constructed on the basis of similarity coefficient clearly divided the genotypes into two major clusters. In most of the crosses the protein profile was more likely to the maternal parent with few bands from the male parent. Presence and/or absence of unique bands were also recorded in crosses which might be because of cis/trans regulation for gene expression and protein synthesis.

\section{Introduction}

Drought is generally accepted to be the most widespread abiotic stress experienced by crop plants, and is becoming an increasingly severe problem in many regions of the world. Each year, drought strikes more than half of the area sown to wheat in the developing world. Thirty seven percent of the area of developing countries consists of semi-arid environment in which available moisture constitutes a primary constraint on wheat production. If prediction is right, an even large expanse of land will become parched every year owing to global warming, urbanization and deforestation. As conditions worsen, farmers will need varieties that tolerate drought and are more responsive to farming practices with better water use efficiency. The effects of drought on crop plants are complex and variable and are greatly accentuated by a number of interacting factors. The onset of drought in general has been observed to reduce germination, emergence, hypocotyl length, water use efficiency and the mobilization of dry matter reserve even at early growth stages (Richards and Thurling, 1978). Wheat is one of the major staple food crops throughout the world. 
Because of modern breeding, it has been realized that the genetic diversity in wheat has increasingly narrowed. Narrow genetic base hamper the pace of crop improvement programme and ultimately gain. It is difficult to breed for adaptation to abiotic and biotic stresses with the population having narrow genetic base (Ahmed et al., 2008). Therefore, it becomes necessary to assess the genetic diversity in wheat in order to enrich the gene pool and broaden the genetic base for future breeding programme. Morphological traits are being used to assess the genetic diversity but they are highly influenced by environmental fluctuations. Use of biochemical marker for genetic diversity studies have received much attention because of cheap, easy in set up and abundance in nature (Masood et al., 2004).

Protein markers could be very successfully used to verify the identity of a variety. If a suitable protocol is standardized, it can be used with equal reproducibility at any time and any location. So such markers can be used to identify parents and to test hybridity of $F_{1} S$ (Akhare et al., 2007). Among the biochemical markers the SDS-PAGE is widely used due to its simplicity and effectiveness for describing the genetic structure of crop germplasm. Identification of different germplasm of is essential when diverse accessions of crop germplasm are to be characterized, newly developed cultivars are to be registered and purity of a variety is to be determined.

Use of biochemical markers for maintaining the genetic purity of line and hybridity of $F_{1} \mathrm{~s}$ has also been reported earlier (Bhatt and Khanna, 2006; Pallavi et al., 2010; Geetha and Balamurugan, 2011; Sharma et al., 2015). Therefore, the present investigation was undertaken to study utility of biochemical marker as an alternative method for assessment of diversity and distinguishing the $\mathrm{F}_{1} \mathrm{~s}$ and parents.

\section{Materials and Methods}

SDS-PAGE discontinuous system was used to observe the protein banding pattern of the parents and their respective $\mathrm{F}_{1}$ 's. The procedure followed was as per the protocol of Laemmli (1970) with some modifications suggested by Lawrence and Shepherd (1980).

\section{Experimental material}

The experimental material used for the study consisted of thirteen drought tolerant, three drought susceptible wheat genotypes and their thirty two $\mathrm{F}_{1}$ 's produced by crossing of these diverse genotypes.

\section{Experimental method}

\section{Extraction of total seed protein}

The total seed storage protein extraction was done according to the method described by Singh et al., (1991). One grain (about $30 \mathrm{mg}$ flour) was crushed to fine powdered form and then added $400 \mu \mathrm{l}$ extraction buffer $(\mathrm{pH}$ 6.8) containing 2 per cent $\beta$-mercaptoethanol and vortexed briefly for 1 to 2 minutes. The tubes were incubated at $60^{\circ} \mathrm{C}$ for 30 minutes and cooled to room temperature. $25 \mu \mathrm{l}$ dye was added to each tube and the contents were centrifuged for 10 minutes at 10,000 rpm. The supernatant was used for loading the sample in the well of the gel for electrophoresis.

\section{Preparation of gels}

The $8.0 \%$ stacking and $10 \%$ separating gels was prepared from the stock solutions.

APS (10\%) was added to separating gel mix just before pouring the gel solution between the plates. $20 \mu \mathrm{l}$ sample was loaded in each well and the electrodes were connected with the power supply. Initially the current was set at $100 \mathrm{v}$ and $26 \mathrm{~mA}$ current for 60 minutes. 
Later on it was increased to $40 \mathrm{~mA}$ with constant voltage at $120 \mathrm{v}$.

Staining, destaining and documentation of gel

Gel was transferred to the staining solution tray after completion of electrophoresis for overnight. Next day $3 \% \mathrm{NaCl}$ solution was used for destaining as described by Sreeramulu and Singh (1994). The photographs of gels were taken on Alpha Imager gel documentation system.

\section{Analysis of gels}

The Rf value was calculated with the help of Alpha Imager, a software for gel documentation.

Rf = Path travelled by the bands / Path travelled by the dye front

The protein profiles were also score on the basis of presence and absence of bands. The 01 binary data was analyzed by the NT-SYS 2.0 software for diversity analysis.

\section{Results and Discussion}

Seed storage proteins are encoded by many multigeneic loci and the production of a single locus comprised of several electrophoretically separable bands. The procedure has been standardized according to crop for different protein fractions. In present study thirteen drought tolerant and three drought susceptible genotypes of wheat and their thirty two $F_{1} s$ were used for diversity analysis and characterization by total soluble seed proteins separated on SDS-PAGE. The protein banding profile and its zymogram is presented in figure 1, 2 and 3. Rf values were calculated for each band. The details of banding profile on the basis of $\mathrm{Rf}$ value was given in Table1.
The total number of bands varied from 9-17 with $\mathrm{Rf}$ value from 0.11 to 0.76 . Most of the bands present in maternal parent were found in $F_{1}$ while there were few bands those were common in paternal parent and $\mathrm{F}_{1} \mathrm{~s}$. There was presence of few unique bands in $F_{1} s$ those were not found in the either of the parents. Three bands of $\mathrm{Rf}$ value $0.10,0.14$ and 0.16 were found only in crosses and absent in either of the parents. A reverse situation was also observed where bands present in both the parents were not found in $\mathrm{F}_{1} \mathrm{~s}$. Bands of $\mathrm{Rf}$ value $0.10,0.15,0.28,0.31,0.40$ and 0.76 were found in the parents but not found in the respective crosses.

\section{Diversity analysis}

Electrophoresis of protein is a powerful tool for identification of genetic diversity and the SDS-PAGE is predominantly considered as a consistent technology because seed storage protein are highly independent of environmental fluctuations (Javid et al., 2004, Iqbal et al., 2005). Diversity is pre-requisite for planning a breeding programme. The banding profile (Fig 1) was scored on absence and presence (0-1) of bands and the data was analyzed by NT-SYS software for diversity analysis. The diversity in seed storage protein has also been reported by Khan et al (2002), Kakai and Kahrizi (2011) in wheat. The parental lines in present investigation showed wide range of variability. The similarity coefficient ranged from 0.985-0.632 (Fig 4). The minimum similarity coefficient was found between PBW 175 and NIAW 34 (0.632) Followed by VL 804 and NIAW 34 (0.647). The maximum similarity was found between VL 804 and VL 802 (0.985) and VL 802 and UP 2572 (0.985). Low value of similarity is an indicative of high level of diversity. The high level of diversity is because of their diverse origin. Highly diverse genotypes can be used as potential donors for improvement programme and can also be used for the 
development of diverse gene pools for exploitation of heterosis. Jangid et al., (2017) used SDS-PAGE for diversity studies among released varieties and crosses developed through diallel mating design in mustard.

The dendrogram constructed on the basis of similarity coefficient clearly divided the genotypes into two major clusters (Fig 6). Both the clusters comprised of 8 genotypes each at 0.71 similarity coefficient. Group I can be subdivided into 2 sub groups. Subgroup I a with genotypes VL-80.2, 804, UP2572 whereas subgroup I b comprised of PBW 175, PBW 65, PBW 373, UP 2425 and UP 2338. The genotypes in subgroup I a were suitable for cultivation in the hills of Uttarakhand. PBW175, PBW 65, PBW 373, UP 2425, UP 2338 are recommended for plains areas. All the Genotypes having gene for drought/heat tolerance belongs to the group II. Group II is further subdivided into 3 subgroups. Group II a comprised of 3 genotypes viz; WH 730, Job666 and NI 5439. NP-846, NIAW34 and HI 385 belong to subgroup II $b$ and PBN-51 and Halna constituted II c. Such clustering helps in grouping the genotype in divserse gene pools for future breeding programmes. The application of protein profiling in germplasm characterization and their use a genetic markers have been widely and effectively used to determine the diversity, taxonomy and evolutionary aspects of several crops (Sharma et al., 2015; Gafoor et al., 2002; Ahmad et al., 2010; Ullah et al., 2016 and Singh et al., 2017)

\section{Hybridity of $F_{1} S$ and identification of cultivars}

The parents and their $\mathrm{F}_{1}$ 's were compared for their protein banding pattern to observe the hybrid nature of $\mathrm{F}_{1}$ 's (Akhare et al., 2007 and Pallavi et al., 2010). The total number of bands varied from 9-17 with arrange of 3000 $\mathrm{kd}$ to $20,100 \mathrm{kd}$. The results showed that the presence of bands from both the parents was found in the $F_{1}$ 's that showed that the $F_{1}$ 's were the result of the cross between drought tolerant and drought susceptible parents (Fig 5). A combined dendrogram of parents and $F_{1} S$ (Fig 7) showed that the protein profile of almost all the $F_{1} s$ are intermediate to their parental profiles but made cluster with the female parent. The reason being most of the bands were contributed by the female parent.. In few crosses the profile of $\mathrm{F}_{1} \mathrm{~s}$ was identical to their respective female parent. Such a condition limits the application of SDS-PAGE for identification and characterization. Findings of Jaiswal and Agrawal 1990 also reported similar findings that banding pattern of protein extracted from seeds could not present a clear spectrum. In Some crosses new bands were observed that were not present in either of the parents, whereas there were cases where, the bands found in both the parents were absent in the crosses. Such unique cases were an indication towards the new nuclearcytoplasmic interaction for expression of proteins.

Protein profiling of selected genotypes have been found effective to differentiate the different genotypes. The tolerant and susceptible parents could be differentiated on the basis of bands profile The bands of $\mathrm{Rf}$ value $0.26,0.31,0.53,0.63$ and 0.72 were present in tolerant parents, while bands of $\mathrm{Rf}$ value $0.09,0.17$ and 0.44 were present in drought susceptible genotypes. So these protein bands having specific Rf value may be useful for separating the two types. Identification of wheat genotypes including ILC-195, CM-2000and CM-98/99 has also been reported by protein markers (Zeb et al., 2006). The utilization of wheat endosperm protein through SDS-PAGE was reported as a valuable tool for assessment of genetic diversity and cultivar identification that help in wheat breeding programme (Khan and Ali, 2014). 
Table.1 Protein profile of wheat parental lines and $\mathrm{F}_{1} \mathrm{~s}$ by SDS PAGE

\begin{tabular}{|c|c|c|c|c|c|c|c|c|c|c|}
\hline $\begin{array}{c}\text { S } \\
\text { No }\end{array}$ & Name of cross & $\begin{array}{l}\text { Range of } \\
\text { bands in } \mathrm{F}_{1} \mathrm{~s}\end{array}$ & Bands in $\mathrm{F}_{1} \mathrm{~S}$ & $\begin{array}{l}\text { Common bands in } \\
\mathrm{F}_{1} \mathrm{~s} \text { and female } \\
\text { parent }\end{array}$ & Bands in female Parent & 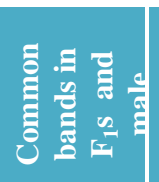 & Band in male parent & Common in all & 过 & 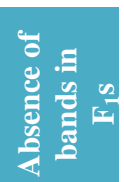 \\
\hline 1 & VL804/UP 2425 & 0.13 to 0.72 & $\begin{array}{l}0.13,0.16,0.20,0.22, \\
0.26,0.31,0.37,0.40, \\
0.50,0.53,0.63 \text { and } \\
0.72\end{array}$ & $\begin{array}{l}0.13,0.20,0.22,0.26 \\
0.31,0.37,0.40,0.50 \\
0.53,0.63 \text { and } 0.72\end{array}$ & $\begin{array}{llll}0.13, & 0.20, & 0.22, & 0.26 \\
0.31, & 0.37, & 0.40, & 0.50 \\
0.53, & 0.63 \text { and } 0.72\end{array}$ & $\begin{array}{l}0.13 \\
0.22 \\
0.37 \\
0.50\end{array}$ & 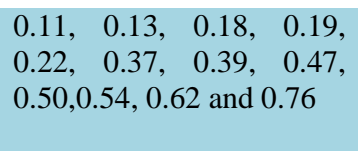 & $\begin{array}{l}0.13, \quad 0.22, \quad 0.37 \\
\text { and } 0.50\end{array}$ & 0.16 & \\
\hline 2 & VL804/PBW 373 & 0.13 to 0.72 & $\begin{array}{l}0.13, \quad 0.16, \quad 0.20, \\
0.22,0.26,0.31,0.37, \\
0.40,0.50,0.53,0.63, \\
0.72\end{array}$ & $\begin{array}{l}0.13,0.20,0.26,0.31 \\
0.40,0.53,0.63 \text { and } \\
0.72\end{array}$ & $\begin{array}{llll}0.13, & 0.20, & 0.22, & 0.26 \\
0.31, & 0.37, & 0.40, & 0.50 \\
0.53, & 0.63 \text { and } 0.72 & \end{array}$ & $\begin{array}{l}0.13 \\
0.22 \\
0.37 \\
0.50\end{array}$ & $\begin{array}{llll}0.09, & 0.13, & 0.18, & 0.22 \\
0.37, & 0.39, & 0.47, & 0.50 \\
0.54, & 0.62 \text { and } 0.76\end{array}$ & $\begin{array}{l}0.13, \quad 0.22, \quad 0.37 \\
\text { and } 0.50\end{array}$ & 0.16 & \\
\hline 3 & VL 802/UP 2338 & $\begin{array}{l}0.13 \text { to } \\
0.72\end{array}$ & $\begin{array}{l}0.13,0.16,0.20,0.22 \\
0.26,0.31,0.37,0.40 \\
0.500 .53,0.63 \text { and } \\
0.72\end{array}$ & $\begin{array}{l}0.13,0.20,0.26,0.31 \\
0.37,0.40,0.53,0.63 \\
\text { and } 0.72\end{array}$ & $\begin{array}{llll}0.13, & 0.20, & 0.22, & 0.26 \\
0.31, & 0.37, & 0.40, & 0.50 \\
0.53, & 0.63 \text { and } 0.72\end{array}$ & $\begin{array}{l}0.22 \\
0.50\end{array}$ & $\begin{array}{llll}0.11, & 0.18, & 0.19, & 0.22 \\
0.28, & 0.30, & 0.39, & 0.47 \\
0.50, & 0.54 \text { and } 0.62\end{array}$ & 0.22 and 0.50 & 0.16 & \\
\hline 4 & VL 802/PBW 373 & 0.13 to 0.76 & $\begin{array}{l}0.13,0.20,0.22,0.26 \\
0.31,0.37,0.40,0.53 \\
0.50,0.63,0.72,0.76\end{array}$ & $\begin{array}{l}0.13,0.20,0.22,0.26 \\
0.31,0.37,0.40,0.50 \\
0.53,0.63 \text { and } 0.72\end{array}$ & $\begin{array}{llll}0.13, & 0.20, & 0.22, & 0.26 \\
0.31, & 0.37, & 0.40, & 0.50 \\
0.53, & 0.63 \text { and } 0.72\end{array}$ & 0.76 & $\begin{array}{llll}0.09, & 0.13, & 0.18, & 0.22 \\
0.37, & 0.39, & 0.47, & 0.50 \\
0.54, & 0.62 \text { and } 0.76\end{array}$ & $\begin{array}{l}0.13, \quad 0.22, \quad 0.37 \\
\text { and } 0.50\end{array}$ & & \\
\hline 5 & VL 802/UP 2425 & 0.13 to 0.76 & $\begin{array}{l}0.13,0.20,0.22,0.26 \\
0.31,0.37,0.40,0.50 \\
0.53,0.63,0.72,0.76\end{array}$ & $\begin{array}{l}0.13,0.20,0.26,0.31 \\
0.40,0.53,0.63 \text { and } \\
0.72\end{array}$ & $\begin{array}{l}0.13,0.20,0.22,0.26,0.31 \\
0.37,0.40,0.50,0.53,0.63 \\
\text { and } 0.72\end{array}$ & 0.76 & 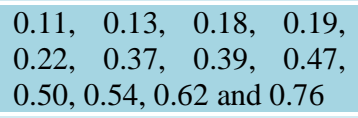 & $\begin{array}{l}0.13, \quad 0.22,0.37 \\
\text { and } 0.50\end{array}$ & & \\
\hline$\overline{6}$ & $\begin{array}{l}\text { UP } \\
373\end{array}$ & 0.13 to 0.72 & $\begin{array}{l}0.13,0.20,0.26,0.31 \\
0.37,0.40,0.50,0.53 \\
0.54,0.63,0.72\end{array}$ & $\begin{array}{l}0.130 .20,0.26,0.31 \\
0.40,0.53,0.63 \text { and } \\
0.72\end{array}$ & $\begin{array}{l}0.13, \quad 0.20, \quad 0.26, \quad 0.31 \\
0.37,0.40,0.50,0.53,0.63 \\
\text { and } 0.72\end{array}$ & 0.54 & $\begin{array}{llll}0.09, & 0.13, & 0.18, & 0.22 \\
0.37, & 0.39, & 0.47, & 0.50 \\
0.54, & 0.62 \text { and } 0.76\end{array}$ & $\begin{array}{lll}0.13, & 0.37 & \text { and } \\
0.50 & & \end{array}$ & & \\
\hline 7 & UP 2572/UP 2425 & 0.13 to 0.72 & $\begin{array}{l}0.13,0.16,0.20,0.26 \\
0.37,0.40,0.50,0.53 \\
0.54,0.63 \text { and } 0.72 \text {. }\end{array}$ & $\begin{array}{l}0.20,0.26,0.40,0.53 \\
0.63 \text { and } 0.72 \text {. }\end{array}$ & $\begin{array}{l}0.13,0.20,0.26,0.31,0.37 \\
0.40,0.50,0.53,0.63 \text { and } \\
0.72\end{array}$ & 0.54 & $\begin{array}{llll}0.11, & 0.13, & 0.18, & 0.19 \\
0.22, & 0.37, & 0.39, & 0.47 \\
0.50, & 0.54, & 0.62 \text { and } & 0.76\end{array}$ & $\begin{array}{lll}0.13, & 0.37 & \text { and } \\
0.50 & & \end{array}$ & 0.16 & \\
\hline 8 & $\begin{array}{l}\text { UP } 2572 / \mathrm{UP} \\
2338\end{array}$ & 0.13 to 0.72 & $\begin{array}{l}0.13,0.22,0.20,0.26 \\
0.37,0.40,0.50,0.53 \\
0.54,0.63 \text { and } 0.72\end{array}$ & $\begin{array}{l}0.13,0.20,0.26,0.37 \\
0.40,0.50,0.53,0.63 \\
\text { and } 0.72\end{array}$ & $\begin{array}{l}0.13, \quad 0.20, \quad 0.26, \quad 0.31 \\
0.37,0.40,0.50,0.53,0.63 \\
\text { and } 0.72\end{array}$ & $\begin{array}{l}0.22 \text { and } \\
0.54\end{array}$ & $\begin{array}{llll}0.11, & 0.18, & 0.19, & 0.22 \\
0.28, & 0.30, & 0.31, & 0.39 \\
0.47, & 0.50, & 0.54 \text { and } & 0.62\end{array}$ & 0.50 & & 0.31 \\
\hline 9 & PBW 65/PBW 373 & 0.11 to 0.76 & $\begin{array}{l}0.11,0.19,0.22,0.30 \\
0.37,0.40,0.47,0.50 \\
0.62 \text { and } 0.76\end{array}$ & $\begin{array}{l}0.11,0.19,0.30 \text { and } \\
0.40\end{array}$ & $\begin{array}{llll}0.11, & 0.19, & 0.22, & 0.30 \\
0.37, & 0.40, & 0.47, & 0.50 \\
0.53, & 0.62 \text { and } 0.76\end{array}$ & & $\begin{array}{llll}0.09, & 0.13, & 0.18, & 0.22 \\
0.37, & 0.39, & 0.47, & 0.50 \\
0.54, & 0.62 \text { and } 0.76\end{array}$ & $\begin{array}{l}0.22, \quad 0.37, \quad 0.47 \\
0.50,0.62 \text { and } 0.76\end{array}$ & & \\
\hline 10 & PBW 65/UP 2425 & 0.11 to 0.76 & $\begin{array}{l}0.11,0.18,0.19,0.22 \\
0.30,0.37,0.30,0.47 \\
0.50,0.62 \text { and } 0.76\end{array}$ & 0.30 and 0.40 & $\begin{array}{llll}0.11, & 0.19, & 0.22, & 0.30 \\
0.37, & 0.40, & 0.47, & 0.50 \\
0.53, & 0.62 \text { and } 0.76\end{array}$ & 0.18 & 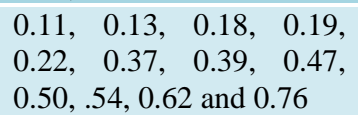 & $\begin{array}{l}0.11,0.19, \quad 0.22, \\
0.37,0.47,0.50, \\
0.62 \text { and } 0.76\end{array}$ & & \\
\hline 11 & PBW 65/UP 2338 & 0.11 to 0.76 & $\begin{array}{l}0.11,0.19,0.22,0.30 \\
0.37,0.40,0.47,0.50\end{array}$ & 0.37 and 0.76 & $\begin{array}{llll}0.11, & 0.19, & 0.22, & 0.30 \\
0.37, & 0.40, & 0.47, & 0.50\end{array}$ & & $\begin{array}{lcc}0.11, & 0.18, & 0.19 \\
0.22,0.28, & 0.30, & 0.39\end{array}$ & $\begin{array}{lll}0.11, & 0.19, & 0.22 \\
0.30, & 0.40, & 0.47\end{array}$ & & \\
\hline
\end{tabular}




\begin{tabular}{|c|c|c|c|c|c|c|c|c|c|c|c|}
\hline & & & & $0.62,0.76$ & & $0.53,0.62$ and 0.76 & & $0.47,0.50,0.54$ and 0.62 & 0.50 and 0.62 & & \\
\hline 12 & $\begin{array}{l}\text { PBW } \\
2338\end{array}$ & 175/UP & 0.11 to 0.62 & $\begin{array}{l}0.11,0.18,0.19,0.22 \\
0.28,0.30,0.37,0.47 \\
\text { and } 0.50\end{array}$ & 0.37 & $\begin{array}{l}0.11,0.18,0.19,0.22,0.28 \\
0.37,0.40,0.47,0.50 \\
0.54,0.62 \text { and } 0.76\end{array}$ & 0.30 & $\begin{array}{l}0.11,0.18,0.19,0.22 \\
0.28,0.30,0.39,0.40 \\
0.47,0.50,0.54 \text { and } 0.62 \text {. }\end{array}$ & $\begin{array}{l}0.11,0.18,0.19 \\
0.22,0.28,0.47 \\
\text { and } 0.50\end{array}$ & & 0.40 \\
\hline 13 & $\begin{array}{l}\text { PBW } \\
2425\end{array}$ & 175/UP & 0.11 to 0.62 & $\begin{array}{l}0.11,0.18,0.19,0.28, \\
0.37,0.47,0.50,0.54 \\
\text { and } 0.62\end{array}$ & 0.28 & $\begin{array}{l}0.11,0.18,0.19,0.22 \\
0.28,0.37,0.40,0.47 \\
0.50, .54,0.62 \text { and } 0.76\end{array}$ & & $\begin{array}{l}0.11,0.13,0.18,0.19 \text {, } \\
0.22,0.37,0.39,0.40 \text {, } \\
0.47,0.50,0.54,0.62 \text { and } \\
0.76 \text {. }\end{array}$ & $\begin{array}{l}0.11,0.18,0.19,0 \\
.37,0.47,0.50 \\
0.54 \text { and } 0.62\end{array}$ & & $\begin{array}{l}0.40 \\
\text { and } \\
0.76\end{array}$ \\
\hline 14 & $\begin{array}{l}\text { PBW } \\
373\end{array}$ & 175/PBW & 0.11 to 0.76 & $\begin{array}{l}0.11,0.18,0.22,0.28 \\
0.37,0.40,0.47,0.50 \\
0.54,0.62 \text { and } 0.76\end{array}$ & $\begin{array}{l}0.11,0.19,0.28 \text {, and } \\
0.40\end{array}$ & $\begin{array}{l}0.11,0.18,0.19,0.22, \\
0.28,0.37,0.40,0.47, \\
0.50,0.54,0.62 \text { and } 0.76\end{array}$ & & $\begin{array}{l}0.09,0.13,0.18,0.22 \\
0.37,0.39,0.47,0.50 \\
0.54,0.62 \text { and } 0.76\end{array}$ & $\begin{array}{l}0.18,0.22,0.37 \\
0.47,0.50,0.54 \\
0.62 \text { and } 0.76\end{array}$ & & 0.40 \\
\hline 15 & WH 7 & /UP 2425 & 0.13 to 0.76 & $\begin{array}{l}0.13,0.19,0.23,0.28, \\
0.33,0.37,0.39,0.41, \\
0.46,0.49,0.54,0.60 \\
0.63,0.72 \text { and } 0.76\end{array}$ & $\begin{array}{l}0.13,0.23,0.28,0.33 \\
0.41,0.46,0.49,0.60 \\
0.63 \text { and } 0.72\end{array}$ & $\begin{array}{l}0.13,0.19,0.23,0.28,0.33 \\
0.37,0.39,0.41,0.46 \\
0.49,0.54,0.60,0.63,0.72 \\
\text { and } 0.76\end{array}$ & & $\begin{array}{l}0.11,0.13,0.18,0.19 \\
0.220 .37,0.39,0.47 \\
0.50,0.54,0.62 \text { and } 0.76\end{array}$ & $\begin{array}{l}0.19,0.37,0.39 \\
0.54 \text { and } 0.76\end{array}$ & & - \\
\hline 16 & WH 7 & /UP 2338 & 0.13 to 0.76 & $\begin{array}{l}0.13,0.19,0.23,0.28 \\
0.33,0.37,0.39,0.41 \\
0.46,0.49,0.54,0.60 \\
0.63,0.72 \text { and } 0.76\end{array}$ & $\begin{array}{l}\text { value } 0.13,0.23, \\
0.33,0.37,0.41,0.46 \\
0.49,0.54,0.60,0.63 \\
0.72 \text { and } 0.76\end{array}$ & $\begin{array}{l}0.13,0.19,0.23,0.28 \\
0.33,0.37,0.39,0.41 \\
0.46,0.49,0.54,0.60 \\
0.63,0.72 \text { and } 0.76\end{array}$ & & $\begin{array}{l}0.11,0.18,0.19,0.22 \\
0.28,0.30,0.39,0.47 \\
0.50,0.54 \text { and } 0.62\end{array}$ & $\begin{array}{l}\text { value } 0.19,0.28 \\
\text { and } 0.39\end{array}$ & & \\
\hline 17 & JOB 6 & /UP 2338 & 0.13 to 0.76 & $\begin{array}{l}0.13,0.19,0.21,0.23, \\
0.30,0.33,0.37,0.39 \\
0.41,0.46,0.49,0.54, \\
0.60,0.63,0.72 \text { and } \\
0.76\end{array}$ & $\begin{array}{l}0.13,0.21,0.23,0.33 \\
0.37,0.41,0.46,0.49, \\
0.60,0.63,0.72 \text { and } \\
0.76\end{array}$ & $\begin{array}{l}0.13,0.15,0.21,0.23 \\
0.28,0.30,0.33,0.37 \\
0.39,0.41,0.46,0.49 \\
0.60,0.63,0.72 \text { and } 0.76\end{array}$ & 0.19 & $\begin{array}{l}0.11,0.18,0.19,0.22 \\
0.28,0.30,0.39,0.47 \\
0.50,0.54 \text { and } 0.62\end{array}$ & $\begin{array}{l}0.30,0.39 \text { and } \\
0.54\end{array}$ & & 0.28 \\
\hline 18 & JOB 6 & /UP 2425 & 0.11 to 0.76 & $\begin{array}{l}0.13,0.14,0.19,0.21, \\
0.23,0.37,0.39,0.41, \\
0.49,0.60,0.54,0.63, \\
0.72,0.76\end{array}$ & $\begin{array}{l}0.13,0.21,0.23,0.41 \\
0.49,0.60,0.63 \text { and } \\
0.72\end{array}$ & $\begin{array}{l}0.13,0.15,0.21,0.23,0.28 \\
0.30,0.33,0.37,0.39 \\
0.41,0.46,0.49,0.54 \\
0.60,0.63,0.72 \text { and } 0.76\end{array}$ & 0.19 & $\begin{array}{l}0.11,0.13,0.18,0.19 \\
0.22,0.37,0.39,0.47 \\
0.50,0.54,0.62 \text { and } 0.76\end{array}$ & $\begin{array}{l}0.37,0.39 \text {, and } \\
0.76\end{array}$ & 0.14 & \\
\hline 19 & NI 543 & /UP 2425 & 0.13 to 0.76 & $\begin{array}{l}0.13,0.14,0.19,0.21 \\
0.23,0.30,0.33,0.37 \\
0.39,0.41,0.49,0.60 \\
0.63,0.72,0.76\end{array}$ & $\begin{array}{l}0.21,0.23,0.30,0.33 \\
0.41,0.49,0.60,0.63 \\
\text { and } 0.72\end{array}$ & $\begin{array}{l}0.13,0.21,0.23,0.30 \text {, } \\
0.33,0.37,0.39,0.41 \text {, } \\
0.49,0.60,0.63,0.72 \text { and } \\
0.76 \text {. }\end{array}$ & 0.19 & $\begin{array}{l}0.11,0.13,0.18,0.19 \\
0.22,0.37,0.39,0.47 \\
0.50,0.54,0.62 \text { and } 0.76\end{array}$ & $\begin{array}{l}0.13,0.37,0.39 \\
\text { and } 0.76\end{array}$ & 0.14 & \\
\hline 20 & NI 543 & /UP 2338 & 0.13 to 0.76 & $\begin{array}{l}0.13,0.14,0.19,0.21, \\
0.23,0.30,0.33,0.37 \\
0.39,0.41,0.49,0.60 \\
0.63,0.72 \text { and } 0.76\end{array}$ & $\begin{array}{l}0.13,0.21,0.23,0.33 \\
0.37,0.41,0.49,0.60 \\
0.63,0.72 \text { and } 0.76\end{array}$ & $\begin{array}{l}0.13,0.21,0.23,0.30 \text {, } \\
0.33,0.37,0.39,0.41 \text {, } \\
0.49,0.60,0.63,0.72 \text { and } \\
0.76\end{array}$ & 0.19 & $\begin{array}{l}0.11,0.18,0.19,0.22 \\
0.28,0.30,0.39,0.47 \\
0.50,0.54 \text { and } 0.62\end{array}$ & $0.30,0.39$ & 0.14 & \\
\hline 21 & NP 84 & UP 2338 & 0.11 to 0.76 & $\begin{array}{l}0.11,0.13,0.14,0.19 \\
0.21,0.26,0.28,0.35 \\
0.39,0.41,0.46,0.49 \\
0.52,0.59,0.67,0.72 \\
\text { and } 0.76\end{array}$ & $\begin{array}{l}0.11,0.13,0.14,0.19 \\
0.21,0.26,0.28,0.35 \\
0.39,0.41,0.46,0.49 \\
0.52,0.59,0.67,0.72 \\
\text { and } 0.76\end{array}$ & $\begin{array}{l}0.11,0.13,0.14,0.19 \text {, } \\
0.21,0.26,0.28,0.35 \text {, } \\
0.39,0.41,0.46,0.49 \text {, } \\
0.52,0.59,0.67,0.72 \text { and } \\
0.76\end{array}$ & & $\begin{array}{l}0.11,0.18,0.19,0.22, \\
0.28,0.30,0.39,0.47 \\
0.50,0.54 \text { and } 0.62\end{array}$ & $\begin{array}{l}0.11,0.19 \text { and } \\
0.39\end{array}$ & & \\
\hline 22 & NP 84 & UP 2425 & 0.11 to 0.76 & $\begin{array}{l}0.11,0.13,0.14,0.19, \\
0.21,0.26,0.28,0.35\end{array}$ & $\begin{array}{l}\text { value } 0.11,0.13 \\
0.14,0.19,0.21,0.26\end{array}$ & $\begin{array}{l}0.11,0.13,0.14,0.19,0.21 \\
0.26,0.28,0.35,0.39\end{array}$ & & $\begin{array}{l}0.11,0.13,0.18,0.19 \\
0.22,0.37,0.39,0.47\end{array}$ & $\begin{array}{l}0.11,0.13,0.19 \\
0.39 \text { and } 0.76\end{array}$ & & \\
\hline
\end{tabular}




\begin{tabular}{|c|c|c|c|c|c|c|c|c|c|c|}
\hline & & & $\begin{array}{l}0.39,0.41,0.46,0.49 \\
0.52,0.59,0.67,0.72 \\
\text { and } 0.76\end{array}$ & $\begin{array}{l}0.28,0.35,0.39,0.41, \\
0.46,0.49,0.52,0.59 \text {, } \\
0.67,0.72 \text { and } 0.76\end{array}$ & $\begin{array}{l}0.41,0.46,0.49,0.52 \\
0.59,0.67,0.72 \text { and } 0.76\end{array}$ & & $0.50,0.54,0.62$ and 0.76 & & & \\
\hline 23 & $\begin{array}{l}\text { NIAW 34/PBW } \\
373\end{array}$ & 0.10 to 0.76 & $\begin{array}{l}0.10,0.13,0.14,0.21, \\
0.33,0.35,0.39,0.46, \\
0.49,0.52,0.59,0.67, \\
0.72 \text { and } 0.76\end{array}$ & $\begin{array}{l}0.10,0.13,0.14,0.21, \\
0.33,0.35,0.39,0.46, \\
0.49,0.52,0.59,0.67 \text {, } \\
0.72 \text { and } 0.76\end{array}$ & $\begin{array}{l}0.10,0.13,0.14,0.21 \\
0.33,0.35,0.39,0.46, \\
0.49,0.52,0.59,0.67,0.72 \\
\text { and } 0.76 \text {. }\end{array}$ & & $\begin{array}{l}0.09,0.13,0.18,0.22 \\
0.37,0.39,0.47,0.50 \\
0.54,0.62 \text { and } 0.76 .\end{array}$ & $\begin{array}{l}0.13,0.39 \text { and } \\
0.76\end{array}$ & & \\
\hline 24 & $\begin{array}{l}\text { NIAW } \\
2338\end{array}$ & 0.11 to 0.76 & $\begin{array}{l}0.10,0.13,0.21,0.33, \\
0.35,0.39,0.46,0.49, \\
0.52,0.59,0.67 \text { and } \\
0.72,0.76\end{array}$ & $\begin{array}{l}0.10,0.13,0.21,0.33 \text {, } \\
0.35,0.49,0.52,0.59 \text {, } \\
0.67 \text { and } 0.72\end{array}$ & $\begin{array}{l}0.10,0.13,0.14,0.21, .33 \\
0.35,0.39,0.46,0.49, .52 \\
0.59,0.67,0.72 \text { and } 0.76\end{array}$ & & $\begin{array}{l}0.11,0.18,0.19,0.22, \\
0.28,0.30,0.39,0.47, \\
0.50,0.54 \text { and } 0.62 .\end{array}$ & $\begin{array}{l}0.39,0.46 \text { and } \\
0.76\end{array}$ & & \\
\hline 25 & HI 385/PBW 373 & 0.10 to 0.76 & $\begin{array}{l}0.10,0.13,0.14,0.19 \\
0.21,0.28,0.33,0.35 \\
0.39,0.46,0.49,0.52 \\
0.67 \text {, and } 0.72,0.76\end{array}$ & $\begin{array}{l}0.13,0.14,0.19,0.21, \\
0.28,0.33,0.46,0.49, \\
0.52 \text { and } 0.72,0.76\end{array}$ & $\begin{array}{l}0.13,0.14,0.19,0.21,0.28 \\
0.33,0.35,0.39,0.46, .49 \\
0.52,0.59,0.67,0.72 \text { and } \\
0.76\end{array}$ & & $\begin{array}{l}0.09,0.13,0.18,0.22, \\
0.37,0.39,0.47,0.50 \\
0.54,0.62 \text { and } 0.76\end{array}$ & $\begin{array}{l}0.13,0.35,0.39 \\
0.67 \text { and } 0.76\end{array}$ & 0.10 & \\
\hline 26 & HI 385/UP 2338 & 0.11 to 0.76 & $\begin{array}{l}0.11,0.13,0.14,0.19 \\
0.21,0.28,0.33,0.35 \\
0.39,0.46,0.49,0.52 \\
0.59,0.67 \text { and } 0.72\end{array}$ & $\begin{array}{l}0.13,0.14,0.19,0.21, \\
0.33,0.39,0.49,0.52, \\
0.59,0.67 \text { and } 0.72\end{array}$ & $\begin{array}{l}0.13,0.14,0.19,0.21, .28 \\
0.33,0.35,0.39,0.46, .49 \\
0.52,0.59,0.67,0.72 \text { and } \\
0.76\end{array}$ & 0.11 & $\begin{array}{l}0.11,0.18,0.19,0.22, \\
0.28,0.30,0.39,0.47, \\
0.50,0.54 \text { and } 0.62\end{array}$ & $\begin{array}{l}0.28,0.35,0.39 \\
\text { and } 0.46\end{array}$ & & \\
\hline 27 & HI 385/UP 2425 & 0.11 to 0.76 & $\begin{array}{l}0.11,0.13,0.14,0.19 \\
0.21,0.28,0.33,0.35 \\
0.39,0.46,0.49,0.52 \\
0.67 \text { and } 0.72,0.76\end{array}$ & $\begin{array}{l}0.14,0.21,0.33,0.46 \\
0.49,0.52 \text { and } 0.72\end{array}$ & $\begin{array}{l}0.13,0.14,0.19,0.21, \\
0.28,0.33,0.35,0.39 \\
0.46,0.49,0.52,0.59 \\
0.67,0.72 \text { and } 0.76\end{array}$ & 0.11 & $\begin{array}{l}0.11,0.13,0.18,0.19 \\
0.22,0.37,0.39,0.47 \\
0.50,0.54,0.62 \text { and } 0.76\end{array}$ & $\begin{array}{l}0.13,0.19,0.28 \\
0.35,0.39,0.67 \\
\text { and } 0.76\end{array}$ & & \\
\hline 28 & PBN 51/UP 2425 & 0.12 to 0.76 & $\begin{array}{l}0.12,0.17,0.22,0.28, \\
0.30,0.35,0.46,0.49 \\
0.58,0.67 \text { and } 0.72\end{array}$ & $\begin{array}{l}0.30,0.46,0.49,0.58 \\
\text { and } 0.72\end{array}$ & 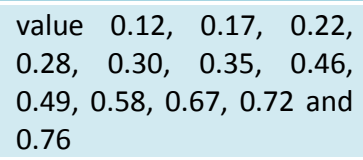 & & 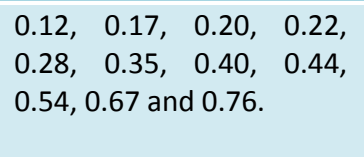 & 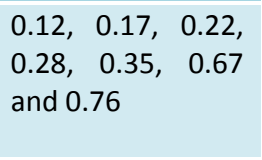 & & \\
\hline 29 & PBN 51/UP 2338 & 0.11 to 0.76 & $\begin{array}{l}0.12,0.17,0.20,0.22, \\
0.28,0.30,0.35,0.46, \\
0.49,0.58,0.67 \text { and } \\
0.72,0.76\end{array}$ & $\begin{array}{l}0.28,0.30,0.49 \text { and } \\
0.72\end{array}$ & $\begin{array}{l}0.12,0.17,0.22,0.28 \\
0.30,0.35,0.46,0.49 \\
0.58,0.67,0.72 \text { and } 0.76\end{array}$ & 0.20 & $\begin{array}{l}0.10,0.12,0.17,0.20 \text {, } \\
0.22,0.35,0.40,0.46 \\
0.54,0.58,0.67 \text { and } 0.76 \text {. }\end{array}$ & $\begin{array}{l}0.12,0.17,0.20 \\
0.22,0.35,0.46 \\
0.58,0.67 \text { and } \\
0.76\end{array}$ & 0.15 & \\
\hline 30 & Halna/UP 2425 & 0.12 to 0.76 & $\begin{array}{l}0.12,0.17,0.20,0.22, \\
0.28,0.35,0.40,0.44, \\
0.46,0.49 \text { and } 0.58 \\
0.67,0.72\end{array}$ & $0.46,0.49$ and 0.58 & $\begin{array}{l}0.10,0.12,0.15,0.17, .20 \\
0.22,0.28,0.35,0.40 \\
0.44,0.46,0.49,0.58 \\
0.67,0.72 \text { and } 0.76\end{array}$ & & $\begin{array}{l}0.12,0.17,0.20,0.22, \\
0.28,0.35,0.40,0.44, \\
0.54,0.67 \text { and } 0.76\end{array}$ & $\begin{array}{l}0.12,0.17,0.20 \\
0.22,0.28,0.35 \\
0.40,0.44,0.67 \\
\text { and } 0.72\end{array}$ & & \\
\hline 31 & Halna/UP 2338 & 0.12 to 0.76 . & $\begin{array}{l}0.12,0.17,0.20,0.22, \\
0.28,0.35,0.40,0.44, \\
0.46,0.49,0.58,0.67, \\
0.72 \text { and } 0.76\end{array}$ & $\begin{array}{l}0.28,0.44,0.49 \text {, and } \\
0.72\end{array}$ & $\begin{array}{l}0.10,0.12,0.15,0.17, \\
0.20,0.22,0.28,0.35, \\
0.40,0.44,0.46,0.49 \\
0.58,0.67,0.72 \text { and } 0.76\end{array}$ & & $\begin{array}{l}0.10,0.12,0.17,0.20 \text {, } \\
0.22,0.35,0.40,0.46 \text {, } \\
0.54,0.58,0.67 \text { and } 0.76 \text {. }\end{array}$ & $\begin{array}{l}0.12,0.17,0.20 \\
0.22,0.35,0.40 \\
0.46,0.58,0.67 \\
\text { and } 0.76\end{array}$ & & 0.10 \\
\hline 32 & Halna/PBW 373 & 0.12 to 0.76 & $\begin{array}{l}0.12,0.17,0.20,0.22 \\
0.28,0.35,0.40,0.44 \\
0.46,0.49,0.58,0.67 \\
\text { and } 0.76\end{array}$ & $\begin{array}{l}0.12,0.20,0.28,0.40 \text {, } \\
0.44,0.46,0.49 \text { and } \\
0.58\end{array}$ & $\begin{array}{l}0.10,0.12,0.15,0.17, \\
0.20,0.22,0.28,0.35, \\
0.40,0.44,0.46,0.49 \\
0.58,0.67,0.72 \text { and } 0.76\end{array}$ & & $\begin{array}{l}0.11,0.15,0.17,0.22 \\
0.35,0.54,0.67 \text { and } 0.76 \text {. }\end{array}$ & $\begin{array}{l}0.17,0.22,0.35 \\
0.67 \text { and } 0.76\end{array}$ & & 0.15 \\
\hline
\end{tabular}


Fig.1 Protein banding profile of parents and $\mathrm{F}_{1}$ 's by SDS-PAGE
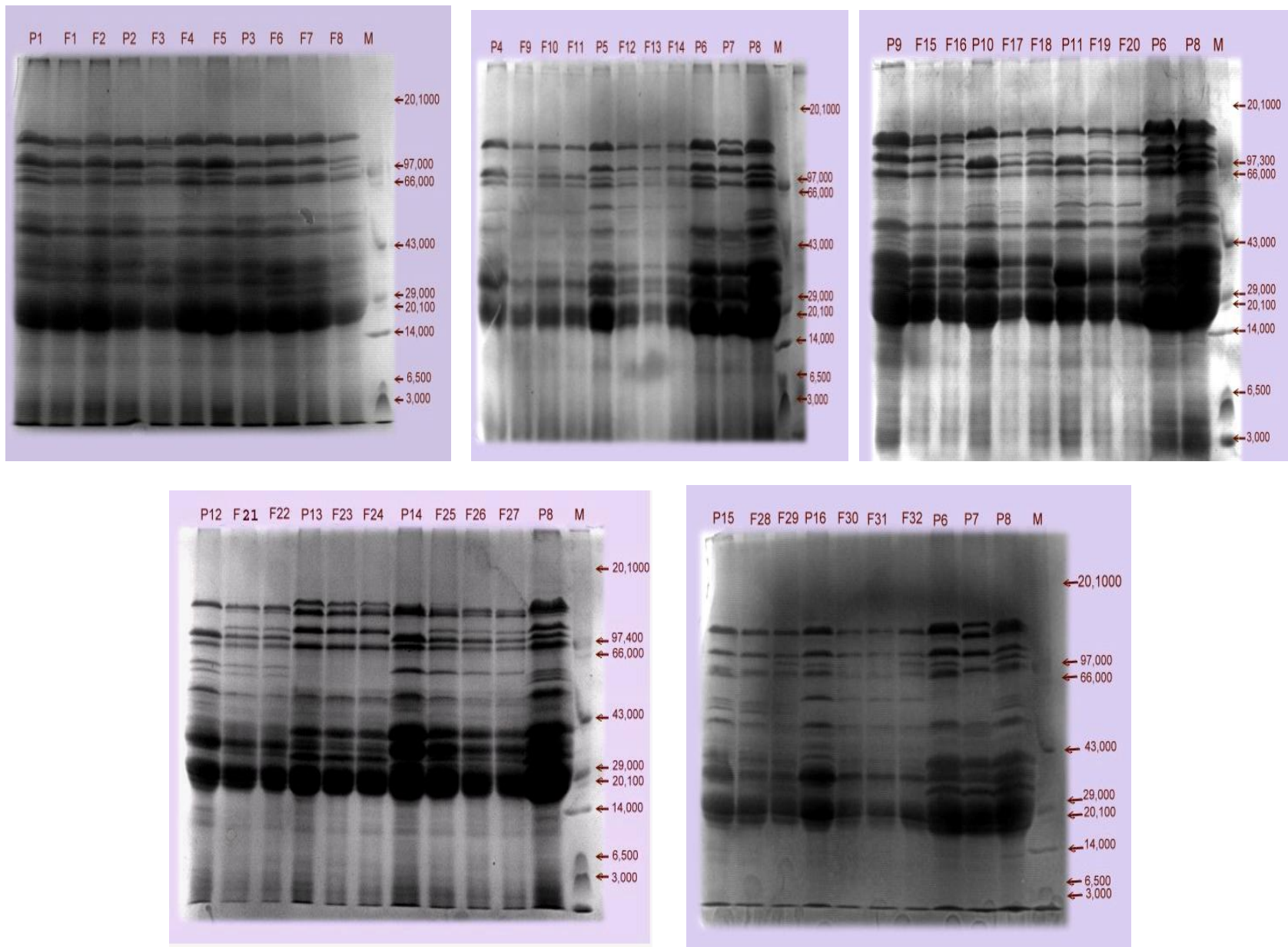

Fig.2 Protein banding profile of parents and $\mathrm{F}_{1}$ 's by SDS-PAGE.

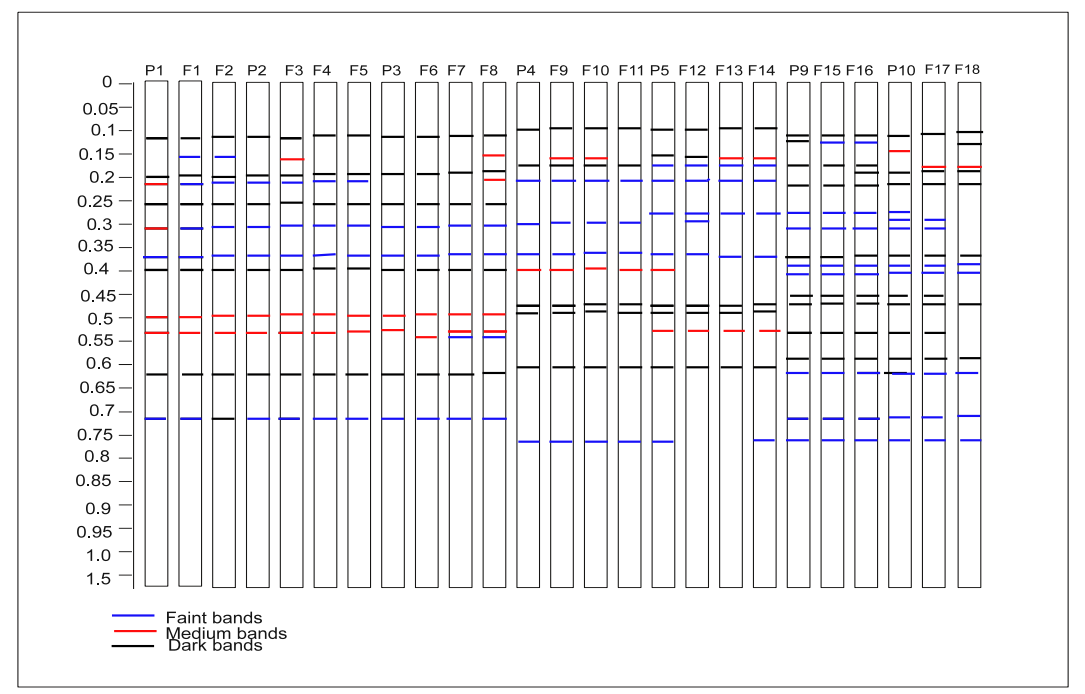


Fig. 3: Protein banding profile of parents and $F_{1}$ 's by SDS-PAGE.

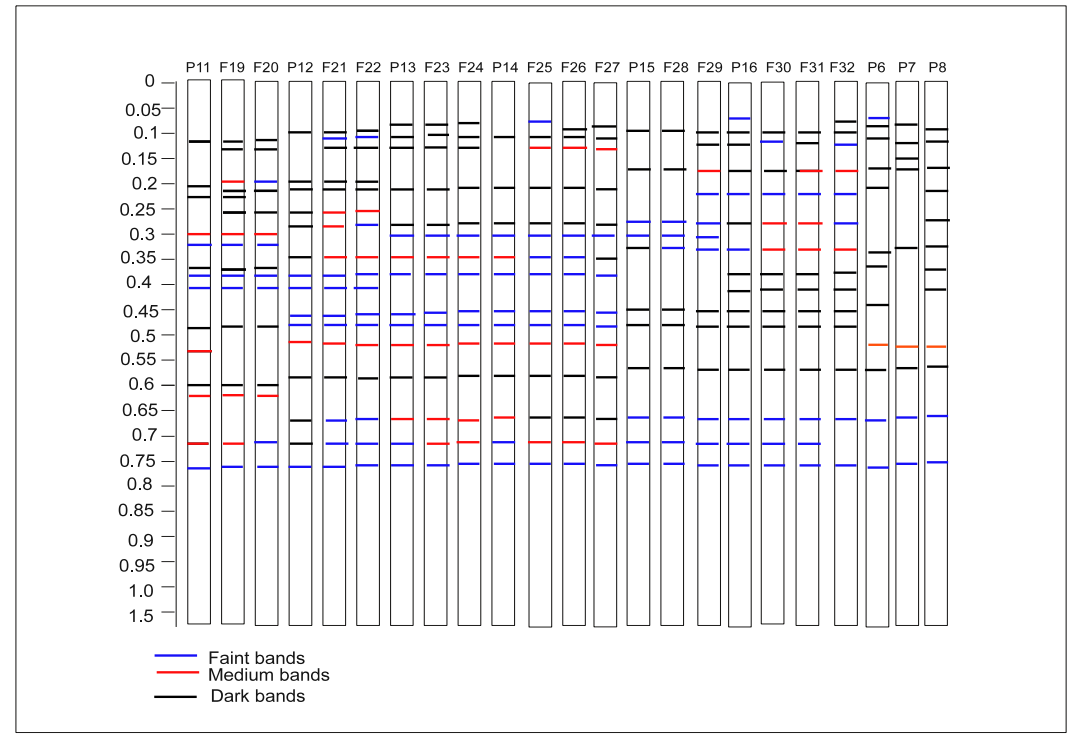

Fig.4 Similarity index of parental lines

\begin{tabular}{|l|l|l|l|l|l|l|l|l|l|l|}
\hline & & & & & & & & & & \\
\hline
\end{tabular}




\section{Fig 5: Combined similarity index of parental lines and $F_{1} S$}

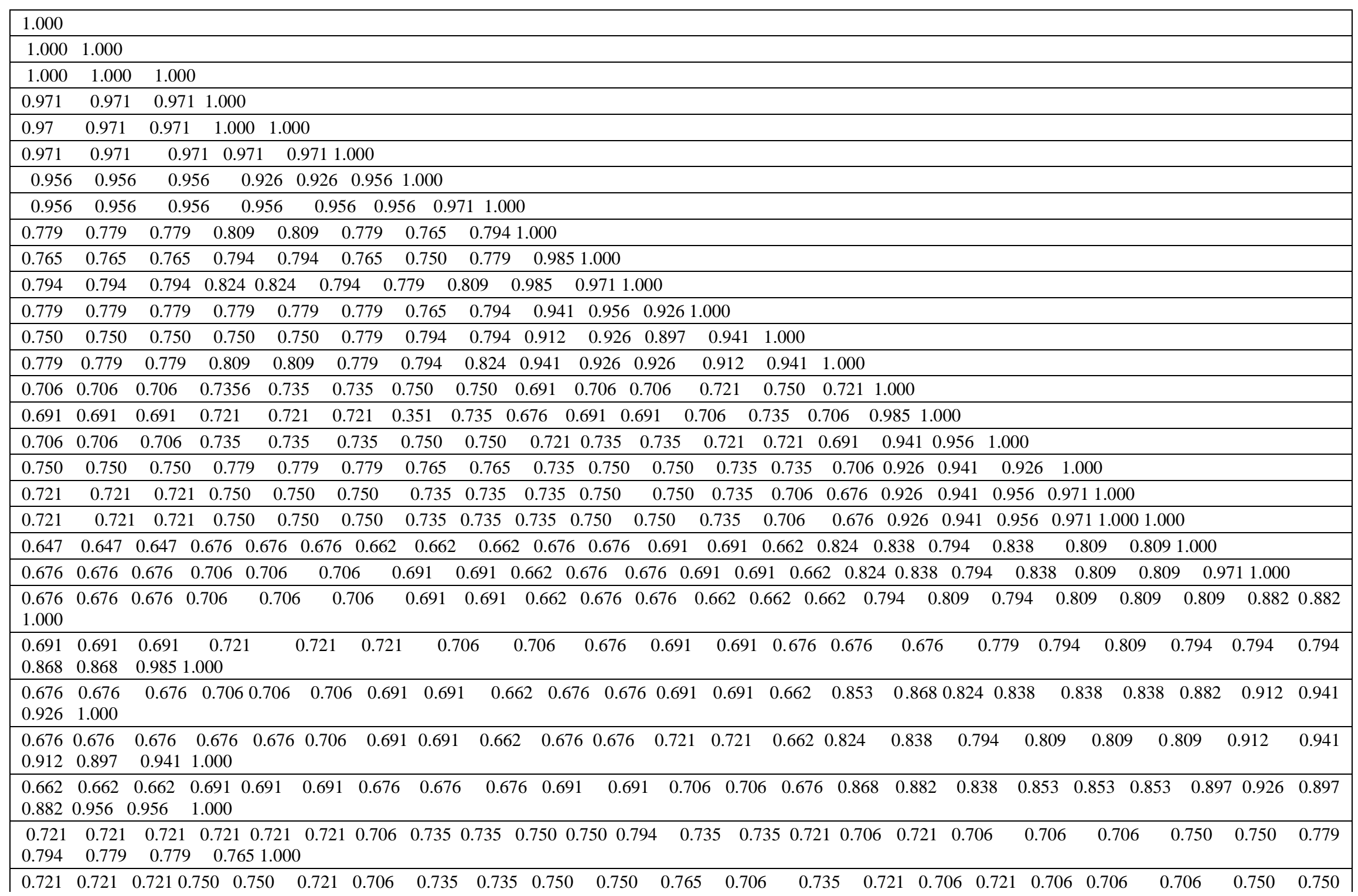




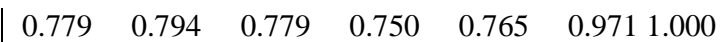

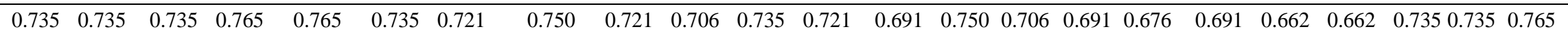
$\begin{array}{lllllll}0.779 & 0.765 & 0.735 & 0.750 & 0.926 & 0.956 & 1.000\end{array}$

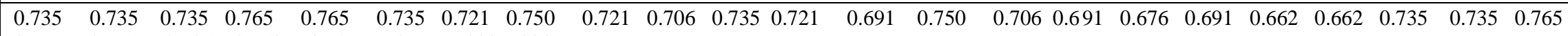

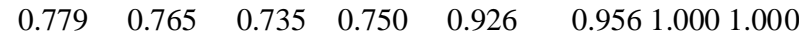

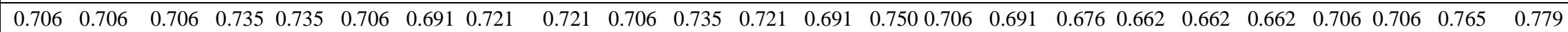
$\begin{array}{llllllll}0.765 & 0.735 & 0.750 & 0.897 & 0.926 & 0.971 & 0.971 & 1.000\end{array}$

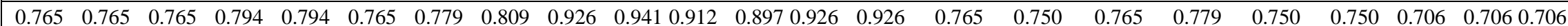
$\begin{array}{llllllllllll}0.721 & 0.706 & 0.706 & 0.721 & 0.691 & 0.691 & 0.676 & 0.676 & 0.676 & 1.000\end{array}$

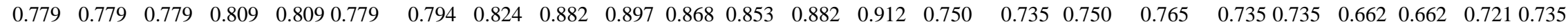

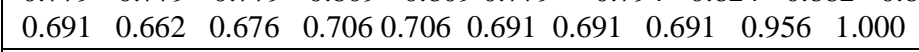

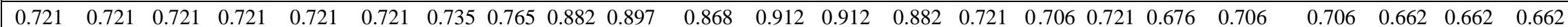
$\begin{array}{llllllllllll}0.676 & 0.691 & 0.721 & 0.706 & 0.735 & 0.735 & 0.691 & 0.691 & 0.721 & 0.897 & 0.853 & 1.000\end{array}$

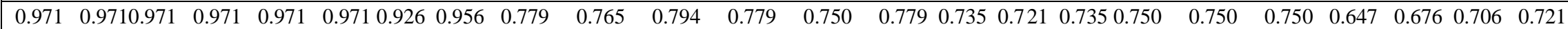

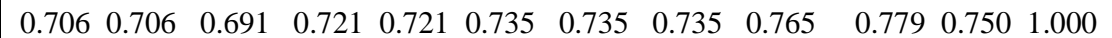

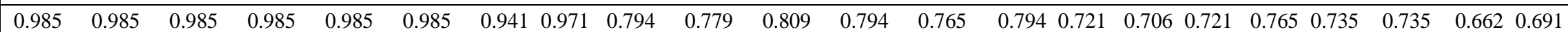

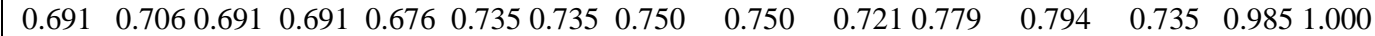

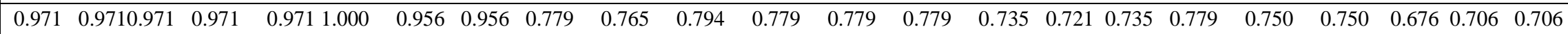
$\begin{array}{lllllllllllllll}0.721 & 0.706 & 0.706 & 0.691 & 0.721 & 0.721 & 0.735 & 0.735 & 0.706 & 0.765 & 0.779 & 0.721 & 0.971 & 0.985 & 1.000\end{array}$

\begin{tabular}{lllllllllllllllllllllll}
\hline 0.794 & 0.794 & 0.794 & 0.824 & 0.824 & 0.794 & 0.779 & 0.809 & 0.956 & 0.941 & 0.971 & 0.897 & 0.868 & 0.897 & 0.706 & 0.691 & 0.735 & 0.750 & 0.750 & 0.750 & 0.676 & 0.676 & 0.676
\end{tabular}

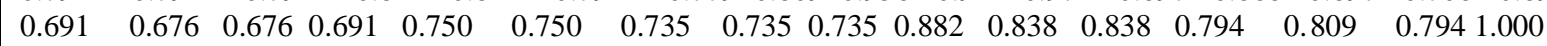

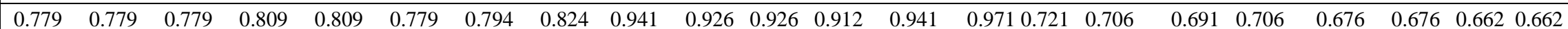

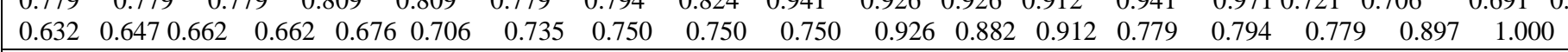

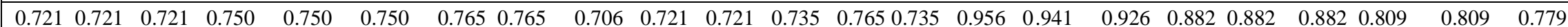

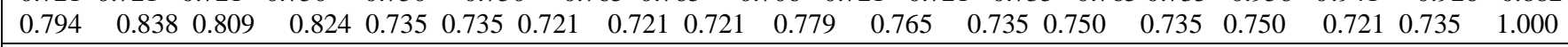

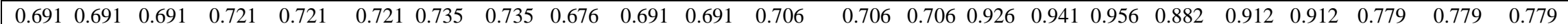

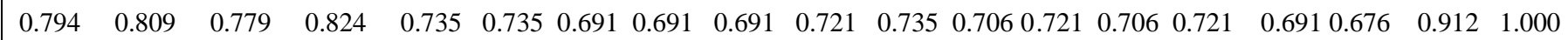

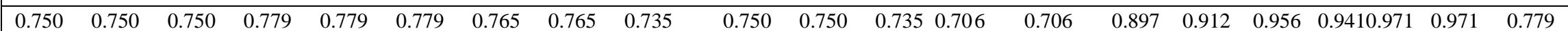

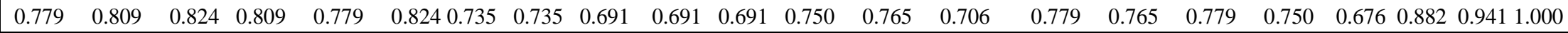

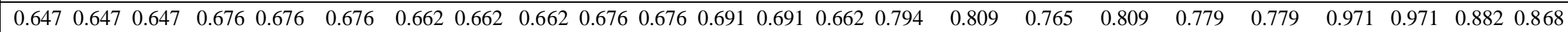

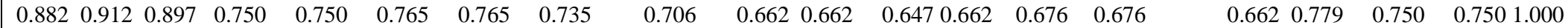

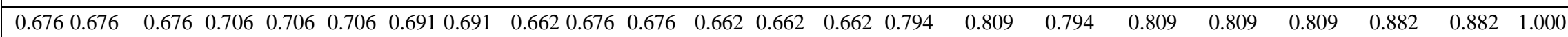

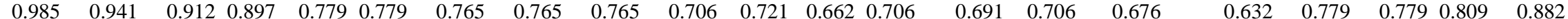
1.000

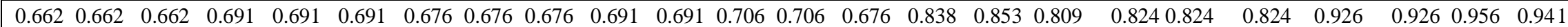

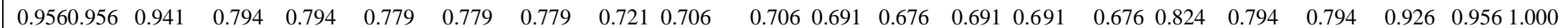

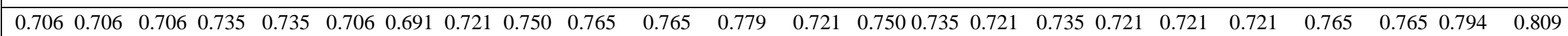

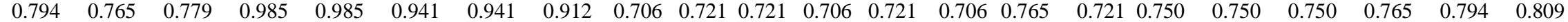
1.000 
Fig.6 Dendrogram showing diversity among parental lines

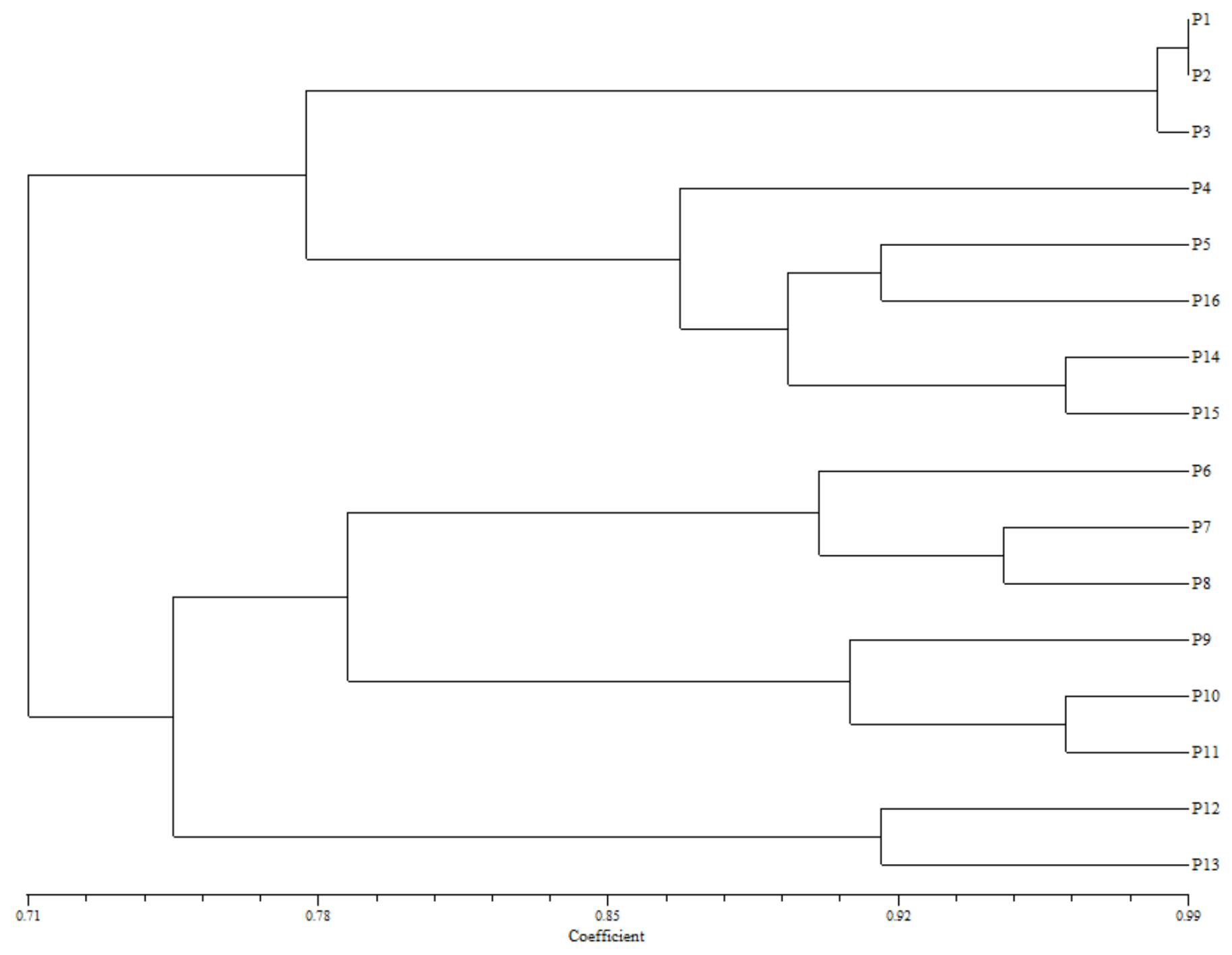


Fig.7 Combine dendrogram of parents and F1s prepared by NT-SYS 2.0

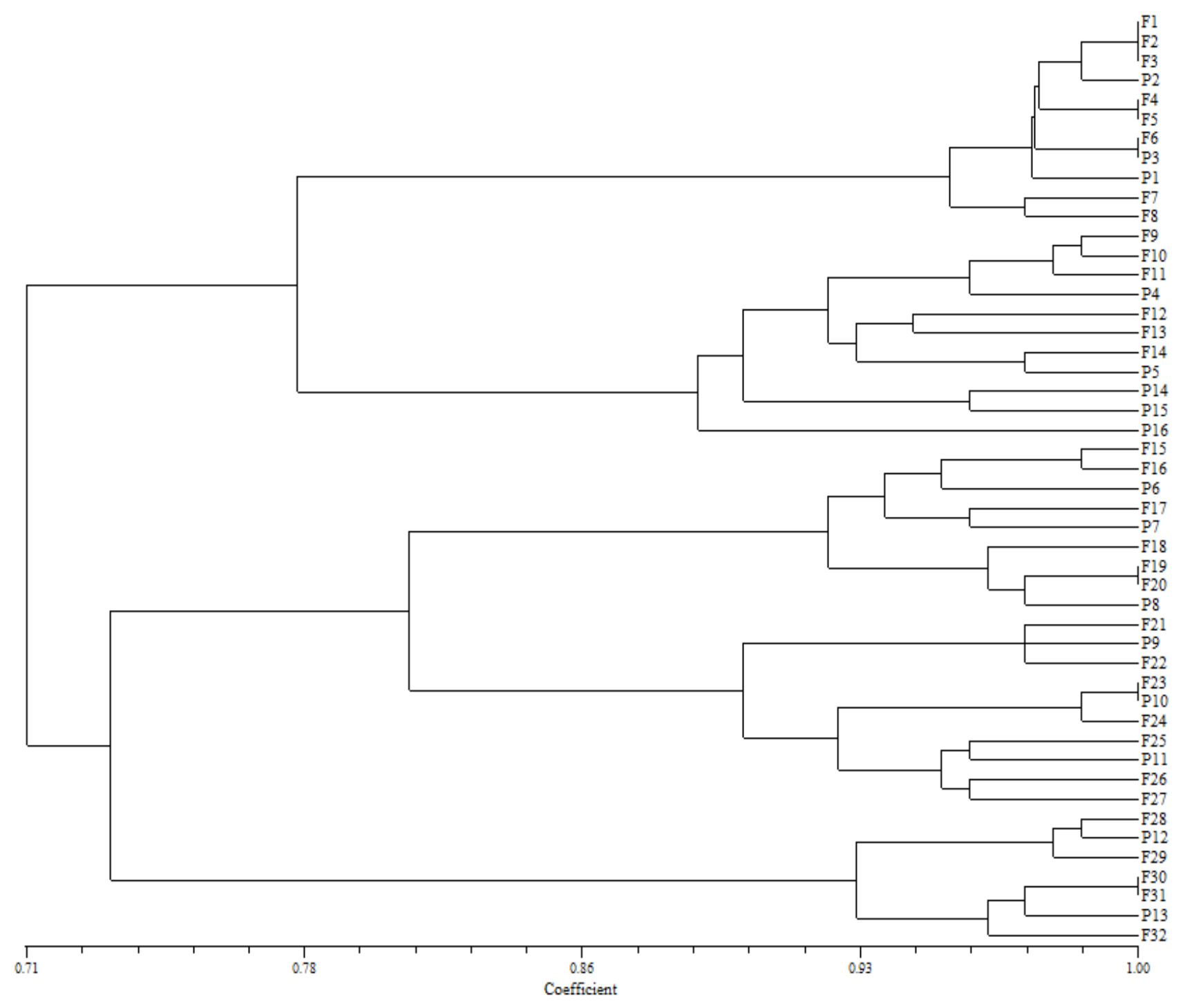


Seed protein pattern can also be used as a promising tool for distinguishing cultivars of particular crop species (Jha and Ohri, 1996; Seferoglue et al., 2006). The SDS-PAGE is considered to be a sensible and reliable technique for species identification.

One band of $\mathrm{Rf}$ value 0.72 was present in all the tolerant parents and $F_{1}$ 's but absent in the drought susceptible parents, so the protein corresponding to $0.72 \mathrm{rf}$ value may be responsible for the drought tolerance. After validation this band can be used as a marker for drought related studies and breeding programmes (Balass et al., 1992; Ekramoddoullah and Tan, 1998; Pattanaik and Kole, 2002 and Kour, 2005). Specific protein profiling for target trait was used for quality assessment of cultivars (Katyal et al, 2018).

Presence of unique bands in some genotypes could be used for the characterization and identification of varieties as well as hybrids. Presence of unique bands in $F_{1}$ 's is an indicative of new genetic constitution as a result of recombination. New genetic constitution causes formation of new protein and ultimate development of a new band that was not present in either of the parent. The same may the reason for absence of band where new genetic architecture leads to the no translation. Unique bands were found in cross VL 804/UP 2425, VL804/ PBW 373,VL 802/ UP 2338 and UP 2572/UP 2338 at Rf value 0.16, Job 666/UP 2425, NI5439/UP 2425 and NI 5439/UP 2338 at 0.14 , HI 385/ PBW 2338 at 0.10 and PBN-51/UP2338 at Rf value 0.15 .

Absence of bands was reported in cross UP 2572/UP 2338 at 0.31 , PBW 175/UP 2338 at 0.40 , PBW 175/UP 2425 at $0.40,0.76$, PBW 175/PBW 373 at 0.40 , JOB 666/UP 2338 at 0.28, Halna/UP 2338 at 0.10 and Halna/PBW 373 at $0.40 \mathrm{Rf}$ value respectively. Anuradh et al., (1990) in pearl millet, Nagaraja et al., (2000) and Chauhan et al., (2002) in sorghum, Limbu et al., (2013) in Indian mustard, Sharma and Krishna (2017) in cow pea and Alice et al., (2017) in chilli mentioned SDS-PAGE as a useful protein marker for varietal identification.

Seed protein is always a reliable method for examination of genetic diversity, characterization and identification of genotypes. In other words it emerged as a powerful tool to assess inert-and inter species variation (Sofalian et al., 2015). Studies on alleleic diversity indicated the expansion of SDS-PAGE as biochemical markers for variable purposes (Kakaei, 2018). It is effectively and widely used in insuring the genetic purity of lines as well as hybrids i.e. contributing significantly towards maintenance breeding of cultivars and ensuring the supply of quality seed. In wheat seed storage protein profile could be used as protein marker in the studied of diversity, hybridity, characterization, and identification of adapted cultivars thereby improving the efficiency of wheat breeding programme and varietal development. It is suggested that other complementary biochemical analysis like 2D electrophoresis must be carried out on genotypes with the same electrophoretic pattern in order to have more precise diverse profiles.

\section{References}

Ahmad, M. F., Iqbal, M., Masood, M. S., Rabbani, M. A. and Munir, M., 2010. Assessment of genetic diversity among Pakistani wheat (Triticum aestivum L.) advanced breeding lines using RAPD and SDS-PAGE. Electronic $\mathrm{J}$ of Biotechnolgy. 3 (3).

Ahmed, Kaleem, Ahmed, Aleem, Abbas, Zaheer, Gulfraz, Muhammad, Masood, Muhammad, Shahid, Kisana, Nafees 
Sadiq, 2008. Genetic diversity in wheat (Triticum aestivum L.) as revealed by SDS-PAGE analysis. International Journal of Applied Agricultural Research. 3 (1): 1-8

Akhare, A., Sakhare, S.B., Kulwal, P.L., Dhumale, D.B. and Khakar, A, 2007. Protein electrophoresis for identification of hybrids and their parents in Sorghum bicolor. Asian J. of Bio. Sci. 3 (1): 176179.

Alice, A K, Dubey, R K, Pandey, A K, Singh, Vikas and Singh, Siddhartha, 2017. Studies on genetic diversity in chilli (Capsicum annum L.) through SDSPAG protein profiling. Int. $J$ of chemical studies. 5 (6): 465-470.

Anuradha, Varier; Veena, Vashisht and Agrawal, P.K., 1990. Identification of pearl millet cultivars using PAGE of soluble proteins and isoenzymes of seed. In International conference on seed science and technology. Feb. 2125, 1990. (Eds. P.K. Agrawal, A.

Balass, M., Cohen, Y. and Joseph, B. M., 1992. Identification of a constitutive 45 $\mathrm{kDa}$ soluble protein associated with resistance to downy mildew in muskmelon (Cucumis melo L.), line PI 124111 F. Physiol. Mol. Plant Pathol. 41(6): 387-396.

Bhatt, U. and Khanna V. K., 2006. Identification of wheat genotypes and their $\mathrm{F}_{1}$ 's in relation to drought tolerance by use of Isozyme analysis. Pantnagar J. of Res. 4(2): 72-76.

Chauhan, P., C. Ram, Mann A., and Sangwan V.P., 2002. Molecular weight analysis of seed proteins of forage sorghum (Sorghum bicolor (L.) Moench). Seed Sci. Technol. 30(1): 11-16.

Ekramoddoullah, A. K. M. and Tan, Y., 1998. Differential accumulation of proteins in resistant and susceptible sugar pine (Pinus lambertiana) seedlings inoculated with the white pine blister rust fungus (Cronartium ribicola). Can. J. Pl. Path. 20 (3): 308-318.

Geetha, V. V., and Balamurugan P., 2011. SDS-PAGE electrophoresis in mustard cultivars. International J. of Agricultural research.6 (5): 437-443.

Ghafoor, A., Ahmad, Z., Qureshi, A.S., and Bashir, M., 2002. Genetic relationship in Vigna mungo (L.) Hepper and $V$. radiata (L.) R. Wilczek based on morphological traits and SDS-PAGE, Euphytica. 123: 367-378.

Iqbal, S.H., Ghafoor, A., and Ayub N., 2005, Relationship between SDS-PAGE markers and Ascochyta blightin chickpea. Pakistan Journal of Botany. 37(1): 87-96.

Jaiswal, J. P. and Agrawal, R. L.,1990. Development of laboratory methods for verification of genetic purity of paddy varieties. In International conference on seed science and technology. Feb. 2125, 1990. (Eds. P.K. Agrawal, A. Gaur, Malvika Dadlani and AnuradaVarier), Indian Society of Seed Technology, Division of Seed Science and Technology, IARI, New Delhi: 61.

Jangid, Kuldeep, Kishna, K. R., Parashar, Naresh, Bhatt, Bhawana, Gaur, Arpit and Kumar, Vinod, 2017. Assessment of Genetic Diversity for storage seed protein in a set of release varieties and their diallele set of crosses in Indian mustard using SDS-PAGE. Int. J. Curr. Microbiol. App. Sci. 6(8):2241-2248.

Javid, A., Ghafoor, A., and Anwar, R., 2004, Seed storage protein electrophoresis in groundnut for evaluating genetic diversity. Pakistan Journal of Botany. 36(1): 25-29.

Jha, S.S. and D. Ohri., 1996. Phylogenetic relationships of Cajanus cajan (L) Millsp. (Pigeon pea and its wild relatives based on seed protein profiles. Genetic Resources and Crop Evolution. 43: 275-281. 
Kakaei, Mehdi and Kahrizi, Daninal, 2011. Evaluation of seed storage protein pattern of ten wheat varieties using SDS-PAGE. Biharean Biologist. 5(2): 116-118.

Kakaei Mehndi, 2018. Evaluation of allelic using SDS-PAGE technique in leaf tissue of bead wheat. Iranian Journal of Plant Biology. 9 (4).

Katyal, Mahek, Virdi, Amardeep Singh, Singh, Narpinder, Kaur, Amritpal, Rana, J. C. and Kumari, jyoti, 2018. Diversity in protein profiling, pasting, empirical and dynamic dough rheoloical of meal from different durum wheat accessions. J Food Sci Technol. 55 (4): 1256-1269.

Khan, M. F., Schumann, E., and Weber, W.E., 2002. Characterization of Pakistani wheat varieties for general cultivation in the mountainous regions of Azad Kashmir. Asian Journal of Plant Sciences. 1: 699-702.

Khan, Naeem and Ali, Shahid, 2017. Advances in the detection of genetic diversity in bread wheat (Triticum aestivum L.) using SDS-PAGE analysis. American journal of Agricultural Sciences. 4 (3): 29-36.

Kour A., 2005. Pre-fertilization studies and embryo rescue for the production of wheat haploids by wheat-maize crosses. Thesis, Doctor of Philosophy (Department of Genetics and Plant Breeding), G.B.P.U.A. \& T., Pantnagar. $205 \mathrm{p}$.

Laemmli, 1970. Cleavage of structural proteins during the assembly of the head of bacteriophage T4. Nature. 227: 680685.

Lawrence G.J., and Shepherd K.W., 1980. Variation in glutenin protein Subunits of wheat. Australian J. Bio. Science. 33: 221-233.

Limbu, Nandita, Singh, S. P. and Pant, Usha, 2013. Seed storage profiling of advanced generations of two families in Indian used through SDS-PAGE. Pantnagar J of Research.11 (3): 361364.

Masood, M. S., Asghar, M. and Anwar, R.., 2004. Genetic diversity in wheat landraces from Pakistan based on Polymorphism for high molecular weight Glutenin subunits (HMW-GS). Pakistan J. of Botany. 36 (4): 835-843.

Nagaraja, G. S., Varier, Anuradha, Singh, Upendra and Sharma, S. P., 2000. Characterization of inbred and hybrids of sorghum (Sorghum bicolor L. Moench) by seed and seedling morphology and electrophoresis of seed proteins and isoenzymes. Pl. Varieties Seeds. 13(1): 17-29.

Pallavi, H. M. Ramogowda, K. Bhanuprakhash., Vishwanath, K. and Shadakshari, Y. G., 2010. Evaluation and confirmation of hybridity on the basis of seed proteins and isozymes in sunflower hybrids. Research J. of Agricultural sciences. 1(3): 189-192.

Patnaik, J. and Kole, I. 2002. Detection of a protein marker for screening of MYMV resistant mungbean genotypes. Indian $\mathrm{J}$. Genet. 62(1): 77-78.

Richards, R. A. and Thurling, N., 1978. Variation between and within species of rape seeds (B. Compestris and B. Napus) in respose to drought stress. II Growth and development under natural drought stresses. Australian J. Agric. Res. 29: 479-490.

Seferoglua, S., Seferoglua, H.G., Tekintasa, F. E., and Baltab, F., 2006, Biochemical composition influenced by different locations in Uzun pistachio cv. (Pistacia vera L.) grown in Turkey. Journal of Food Composition and Analysis. 19(5): 461-465.

Sharma, D., Saharan, V., Joshi, A., Jain, D., 2015. Biochemical characterization of bread wheat genotypes based on SDS- 
PAGE. Triticaceae genomics and Genetics. 6(2)

Sharma, D. B, and Krishna, K. R., 2017. Genetic diversity on cow pea (Vigna Umbuiculata) accessions using protein profiling. Int. J. of Pure and Applied Biosciences. 5(2): 491-496.

Singh, B. K., Singh, A. K., Hotti, A. H., Kumar, J. and Singh, S. K., 2017. Diversity analysis through SDS-PAGE of seed storage protein of pea genotypes. Res. Environ. Life Sci.10 (5):449-452.

Singh, D. V., Srivastava, K. D. and Agarwal, R., 1991. Results of coordinated experiments. AICWIP-ICAR. Pp. 7680.

Sofalian, O., Asghari, A. and Firoozi, B., 2015. Identification of seed storage protein in some soybean genotypes using SDS-PAGE. Tar heel Nurse. 25 (2):127-133.
Sreeramulu, G. and Singh, N. K., 1994. High molecular glutenin subunits of Indian wheat cultivars: Association of subunits $5+10$ with the IBL/IRS wheat-rye translocation. J. Cereal Sci. 20: 217225.

Ullah, hidayat, Ahmad, Habib, Shahzad, Armghan, Ali, Ahmad and Ali, Ghulam Muhammad, 2016. Evaluation of allelic variation for HMW glutenin subunits through SDS-PAGE in divers bread wheats. International journal of Biosciences. 9 (1):203-214.

Zeb, A., Zahir, A., Ahmad, T., and Abdumanon, A., 2006. Physiochemical characteristics of wheat varieties growing in the same and different ecological regions of Pakistan, Pakistan Journal of Biological Sciences. 9: 18231828.

\section{How to cite this article:}

Usha Pant and V.K. Khanna. 2018. Diversity Analysis and Hybridity Test of Drought Responsive Wheat Cultivars and Their F1's on the Basis of SDS-PAGE Profiles. Int.J.Curr.Microbiol.App.Sci. 7(06): 3319-3335. doi: https://doi.org/10.20546/ijcmas.2018.706.389 